\title{
Sparse Hair on the Scalp
}

\author{
Hadir Shakshouk, MBBS, MSc
}

\section{Eligible for 1 MOC SA Credit From the ABD}

This Photo Challenge in our print edition is eligible for 1 self-assessment credit for Maintenance of Certification from the American Board of Dermatology (ABD). After completing this activity, diplomates can visit the ABD website (http://www.abderm.org) to self-report the credits under the activity title "Cutis Photo Challenge." You may report the credit after each activity is completed or after accumulating multiple credits.

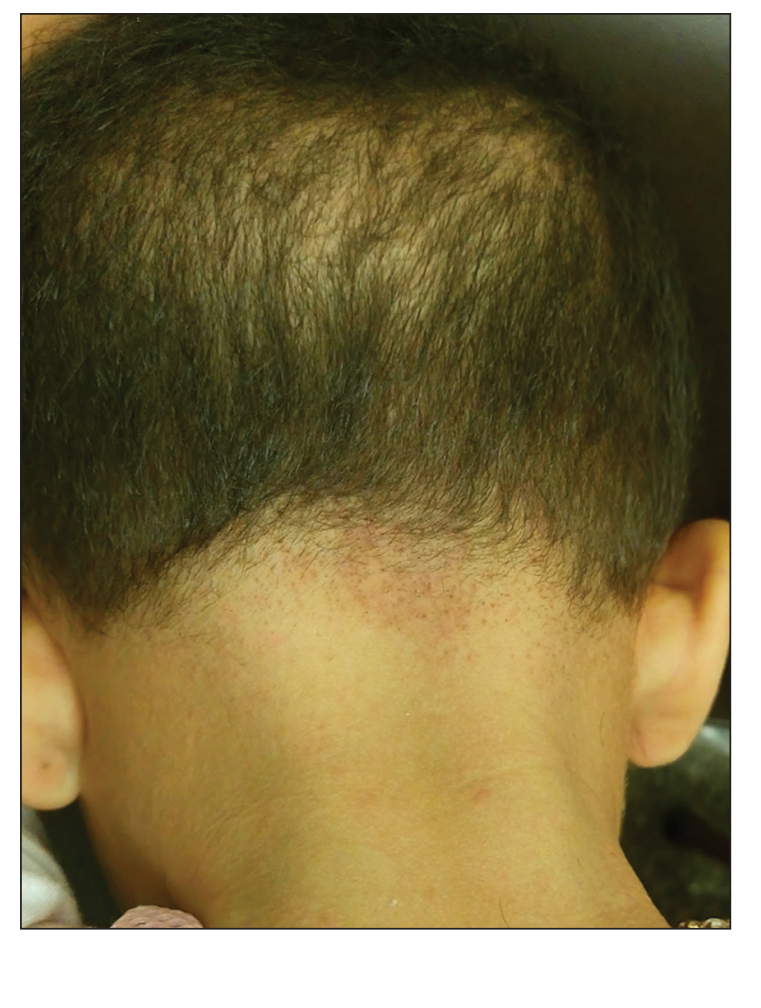

A 5-year-old girl presented to our clinic with sparse scalp hair. Her mother reported thinning of the hair and breakage that appeared shortly after birth. She also reported that the patient's hair was dull, dry, and unable to be grown long. The patient was otherwise healthy. She was born to nonconsanguineous parents, and her family history was unremarkable. Physical examination revealed dry, brittle, and short hairs. The hair was sparser on the occipital area of the scalp, and multiple keratotic papules were noted in this area. No abnormalities were detected on the teeth or nails, and a review of systems was unremarkable. Trichoscopy and light microscopy were performed.

\section{WHAT'S YOUR DIAGNOSIS?}
a. ectodermal dysplasia
b. hypotrichosis simplex
c. monilethrix
d. pili annulati
e. pili torti

From the Department of Dermatology, Andrology and Venerology, Alexandria University, Egypt. The author reports no conflict of interest.

Correspondence: Hadir Shakshouk, MBBS, MSc (drhadir58@gmail.com).

doi:10.12788/cutis.0108 


\section{THE DIAGNOSIS: Monilethrix}

$\mathrm{T}$ richoscopy showed a beaded appearance of the hair shafts (Figure, A). Light microscopy demonstrated normal medullated nodes of hair coupled with internodal, thin, nonmedullated hair at regular intervals (Figure, B). Clinical and trichoscopic findings led to a diagnosis of monilethrix.

Monilethrix is a genetic hair disorder characterized by regular periodic thinning of the hair shafts, giving the strands a beaded appearance. The hair tends to break at these constricted parts, resulting in short hairs. Nodosities represent the normal hair shaft, whereas the constricted points are the site of the defect. The hair tends to be normal at birth and then becomes short, fragile, and brittle within months, leading to hypotrichosis, particularly on the occipital scalp. ${ }^{1}$ Monilethrix also may involve the eyebrows and eyelashes in addition to scalp hair. Follicular hyperkeratotic papules with perifollicular erythema frequently are noted on the occipital area. Monilethrix can be inherited in an autosomal-dominant fashion with mutations involving KRT81, KRT83, and KRT86, which code for the type II hair keratins $\mathrm{Hb} 1, \mathrm{Hb} 3$, and $\mathrm{Hb} 6$, respectively. The autosomal-recessive form is caused by mutations in the DSG4 gene, coding for the desmoglein 4 protein. ${ }^{2}$ Trichoscopy or light microscopy is essential to establish a diagnosis of monilethrix. Trichoscopy is an easy and rapid tool that is utilized to illustrate the beaded appearance of the hair shafts. ${ }^{3}$ Light microscopy shows the distinctive nodes that are medullated, with a normal hair diameter alternating with the internodes, or constrictions, that are nonmedullated and represent the sites of fracture. ${ }^{1}$ Monilethrix can improve by puberty. There is no definitive treatment; however, some patients show considerable improvement on minoxidil. ${ }^{4}$ Treatment with minoxidil was initiated in this patient; however, she was lost to follow-up.

Genetic hair disorders are rare and can be an isolated phenomenon or part of concurrent genetic syndromes. Therefore, thorough clinical examination of other ectodermal structures such as the nails and teeth is crucial as well as obtaining a detailed family history and review of systems to exclude other syndromes. ${ }^{2}$ Hypotrichosis simplex is characterized by hair loss exclusively on the scalp, sparing other ectodermal structures and with no systemic abnormalities. Ectodermal dysplasia is a heterogeneous group of disorders affecting not only the hair but also the teeth, nails, and sweat glands. ${ }^{2}$ Pili torti is another
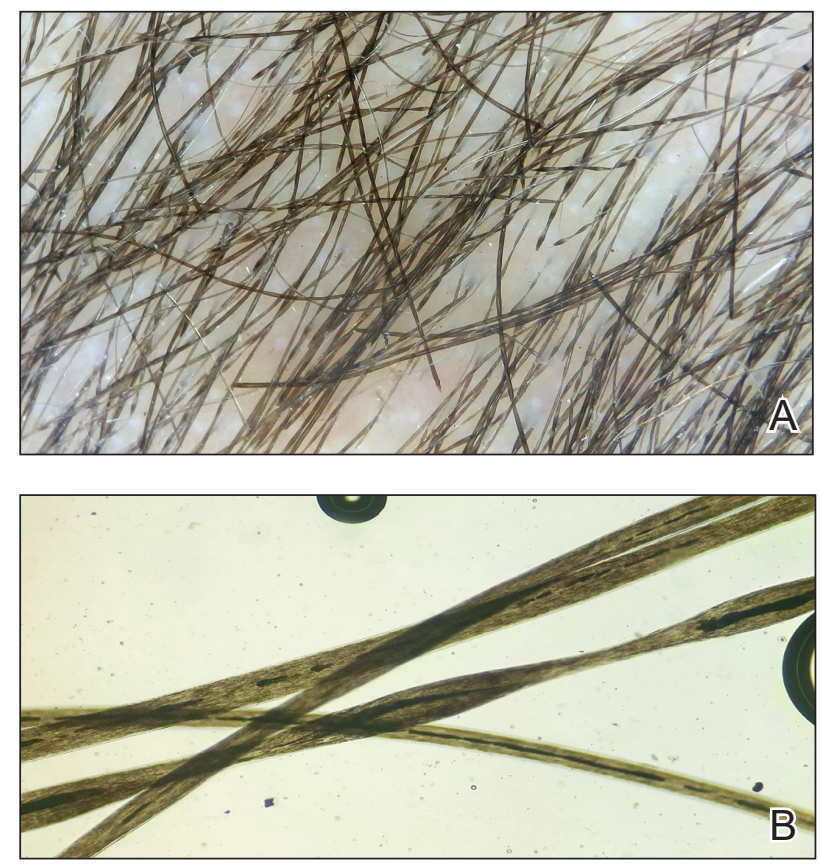

A, Trichoscopy revealed a beaded appearance of the hair shafts with elliptical nodes as well as multiple constrictions and regular intervals. B, Light microscopy showed alternating nodes and cracked areas on the thin part of the hair shaft (original magnification $\times 100$ ).

rare genetic hair disorder that is characterized by twisting of the hair fiber on its own axis. It presents clinically as sparse, depigmented, lusterless hair that is easily broken. Light microscopy demonstrates twists of hair at irregular intervals. Pili annulati is characterized by bright and dark bands when viewed with reflected light. Unlike monilethrix, there is no fragility, and the hair can grow long. ${ }^{5}$

\section{REFERENCES}

1. Mirmirani P, Huang KP, Price VH. A practical, algorithmic approach to diagnosing hair shaft disorders. Int J Dermatol. 2011;50:1-12.

2. Ahmed A, Almohanna H, Griggs J, et al. Genetic hair disorders: a review. Dermatol Ther. 2019;9:421-448.

3. Liu C-I, Hsu C-H. Rapid diagnosis of monilethrix using dermoscopy. Br J Dermatol. 2008;159:741-743.

4. Rossi A, Iorio A, Fortuna MC, et al. Monilethrix treated with minoxidil. Int J Immunopathol Pharmacol. 2011;24:239-242.

5. Singh G, Miteva M. Prognosis and management of congenital hair shaft disorders with fragility—part I. Pediatr Dermatol. 2016;33:473-480. 